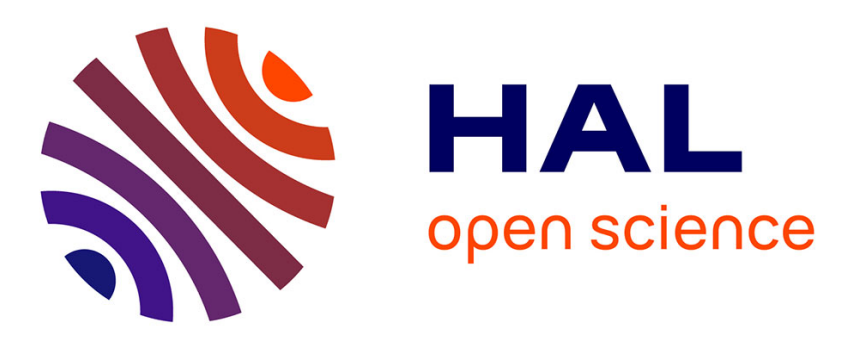

\title{
Modeling of fault gouges with Cosserat Continuum Mechanics: Influence of thermal pressurization and chemical decomposition as coseismic weakening mechanisms
}

\author{
Emmanuil Veveakis, Jean Sulem, Ioannis Stefanou
}

\section{To cite this version:}

Emmanuil Veveakis, Jean Sulem, Ioannis Stefanou. Modeling of fault gouges with Cosserat Continuum Mechanics: Influence of thermal pressurization and chemical decomposition as coseismic weakening mechanisms. Journal of Structural Geology, 2012, 38, pp.254-264. 10.1016/j.jsg.2011.09.012 . hal00688670

\section{HAL Id: hal-00688670 \\ https://hal-enpc.archives-ouvertes.fr/hal-00688670}

Submitted on 12 Jan 2014

HAL is a multi-disciplinary open access archive for the deposit and dissemination of scientific research documents, whether they are published or not. The documents may come from teaching and research institutions in France or abroad, or from public or private research centers.
L'archive ouverte pluridisciplinaire HAL, est destinée au dépôt et à la diffusion de documents scientifiques de niveau recherche, publiés ou non, émanant des établissements d'enseignement et de recherche français ou étrangers, des laboratoires publics ou privés. 


\title{
Modeling of fault gouges with Cosserat Continuum Mechanics: Influence of thermal pressurization and chemical decomposition as coseismic weakening mechanisms
}

\author{
Emmanuil Veveakis*
}

National Technical University of Athens, School of Applied Mathematics and Physics, Theocharis Bld, Iroon Politechniou 5, Zografou, Athens, 15773, Greece Jean Sulem

UR Navier-CERMES, Ecole des Ponts ParisTech, Université Paris-Est, 6,8 Avenue Blaise Pascal, Champs-sur-Marne, 77455, Marne-la-Vallée Cedex 2, France

Ioannis Stefanou

National Technical University of Athens, School of Applied Mathematics and Physics, Theocharis Bld, Iroon Politechniou 5, Zografou, Athens, 15773, Greece

\begin{abstract}
In this paper we study the impact of thermal pressurization and mineral decomposition reactions under seismic deformation conditions (e.g., slip rates of about $1 \mathrm{~m} / \mathrm{s}$ ) triggered by shear heating, to the stability of a saturated fault material. By using higher order continuum considerations, allowing for rotational degrees of freedom to the gouge material, we verify that the micro-inertia of the Cosserat continuum may regularize the ill-posed problem of simple shear of a fault and that the thermal effects promote localization of deformation into ultra-thin shear bands. It is shown that the width of these
\end{abstract}

*Corresponding Author. Email: manolis@mechan.ntua.gr, Tel:+30 2107721373 
structures depends on the parameters of the decomposition reaction considered, obtaining values as low as $100 \mu \mathrm{m}$, in agreement with microstructural evidence from natural and artificial faults. .

Key words: Shear Heating, Cosserat Continuum, Reaction kinetics, Undrained adiabatic shearing, Micro-Inertia

\section{Introduction}

Geomaterials exhibit failure in various patterns, like the propagation of single fractures in otherwise intact rock, crack growth in presence of multiple interacting fractures, initiation and percolation of damage zones under quasistatic and dynamic loading, strain localization into shear- or compaction bands.

The theory describing localized failure has been a direct extension of the classic Mohr's strength of materials theory, and is applied for geomaterials using the so-called Thomas - Hill - Mandel shear-band model (Hill (1962); Mandel (1966)), which was introduced in the early 60s and it was widely publicized by the paper of Rudnicki and Rice (1975). More recently, the mathematical formulation of bifurcation and post-bifurcation phenomena and related instabilities was summarized by Vardoulakis and Sulem (1995) to form the basis of a contemporary continuum theory of failure of geomaterials.

Apart from the theoretical point of view of failure, shear banding has been claimed as the primary failure pattern for faults (Rice (2006)) and landslides (Vardoulakis (2002a)). However, field evidence from exhumed faults reveals that seismic events take place in even narrower zones within shear-bands, formed from post-failure evolution (Chester and Chester (1998)), dominated 
by weakening mechanisms that are considered to be mainly thermal of origin (Rice (2006)). Indeed, field observations suggest that slip in individual events may then be extremely localized, and may occur primarily within a thin shear zone, $<1-5 \mathrm{~mm}$ thick, called the principal slipping zone (PSZ) (Sibson (2003)). This localized shear zone lies within a finely granulated fault core of typically tens to hundreds millimeter thickness, as shown schematically in the idealized description of Fig. 1.

Evidence for that morphology can be found in the North Branch San Gabriel fault (Chester et al. (1993)) and Punchbowl (Chester and Chester (1998)) fault of the San Andreas system in southern California, the Median Tectonic Line fault in Japan (Wibberley and Shimamoto (2003)), and in the Hanaore fault in southwest Japan (Noda and Shimamoto (2005)). Note also that from drilling cores in the Aigion system, central Greece, the fault core of clay size particles consisting of finely crushed radiolarites, extended to about $1 \mathrm{~m}$, was found to be intercepted by a "fresh" distinct slip surface of sub-millimiter size (Sulem (2007); Cornet et al. (2004)).

As perhaps the best characterized case, a thin principal slipping zone was identified along an exposure of the Punchbowl fault at 2 to $4 \mathrm{~km}$ depth, which has accommodated $44 \mathrm{~km}$ of slip (Chester and Chester (1998)). Also, a thin central slip zone was identified by Wibberley and Shimamoto (2003) along the Median Tectonic Line fault. The nominal thickness of such a shear zone is usually of the order of sub-millimeter and, as described by Smith et al (2011), it could be met in calcite-bearing fault rocks even in the absence of pressure-solution and precipitation, providing thus field evidence of extreme localization during coseismic slip in natural faults. On the other hand the 


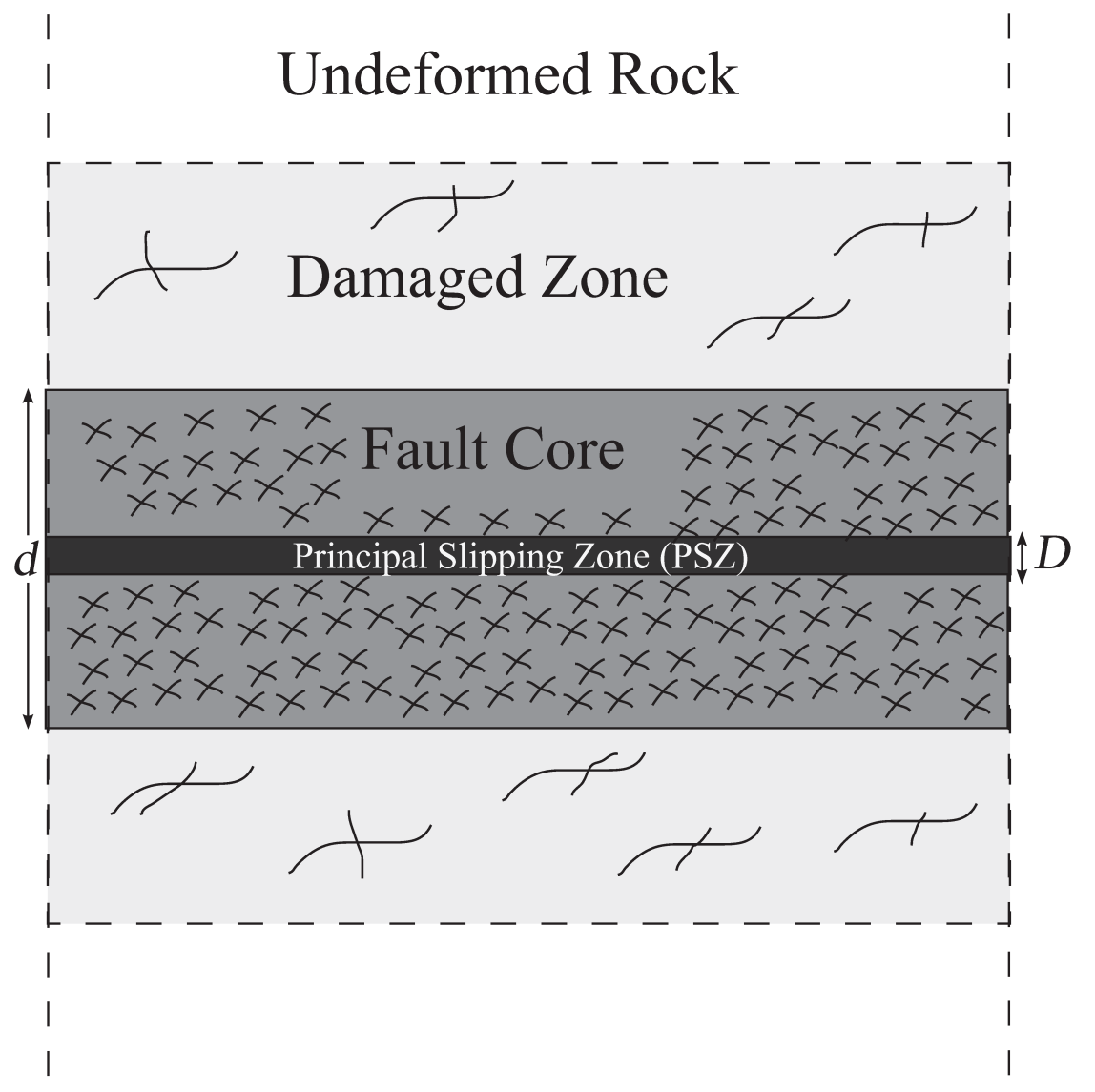

Figure 1: Idealized description of a natural fault zone, as presented by Chester et al. (1993) and Wibberley et al. (2008). The fault core, $d$, is of the order of centimeters, whereas the Principal Slipping Zone (PSZ) D is of the order of millimeter or less. 
thickness of the cataclastic core may vary up to a few centimeters.

In geomechanics there are several studies focusing on the thickness of shear bands in soils. Morgenstern and Tschalenko (1967) calculated that shear bands for a clay, kaolin may have thicknesses of order $10-100$ times a clay platelet size $(\sim 0.5 \mu \mathrm{m})$. For granular materials on the other hand usually use the mean particle diameter, $d_{50}$, is used as a scaling measure, defined for nonuniform size distributions such that $50 \%$ by weight of the particles have larger size.

Under purely mechanical effects, Muhlhaus and Vardoulakis (1987) calculated for sands the thickness of the initial shear band (with thickness $d$ in Figure 1) to be around $d \sim 16 d_{50}$. In any case, this zone seems to be rather wide to be considered as the primary slip surface (Rice (2006)). Indeed, Chester and Goldsby (2003) showed that the nominal thickness of the Punchbowl's cataclastic core varies from 0.6 to $1.1 \mathrm{~mm}$. However, as Rice (2006) mentions: "within this $\sim 1 \mathrm{~mm}$ thick nominal shear zone, most of the shearing seems to have been accommodated within a zone of extreme shear localization having an apparent thickness of $100-300 \mu m$ ". Rice (2006) showed that $d_{50}$ is not always a characteristic length scale for cataclastic and ultracataclastic formations, since apparently $d_{20}-d_{30}$ seems to be more appropriate for modeling the PSZ. Thus, in principle the PSZ represents a very fine shear localization, consisting of ultrafine particles that have usually undergone mechano-chemical degradation (gelification, decarbonation and dehydration reactions, melting, as thoroughly discussed by Di Toro et al. (2011)). Therefore, other mechanisms that are responsible for the formation of these structures and the dynamic weakening of faults should be looked 
after

Since fault zones usually exhibit the presence of fluid interacting with the rock, hence inducing coupled effects including shear heating and pore fluid pressurization, such mechanisms are expected to act as weakening mechanisms during fault slip (Sibson (1973); Lachenbruch (1980); Wibberley and Shimamoto (2005)). These mechanisms have also been suggested for weakening in catastrophic landslides (Vardoulakis (2002a); Veveakis et al. (2007); Goren and Aharonov (2007); Pinyol and Alonso (2010); Goren et al. (2010)). Thermo-poro-mechanical couplings due to shear heating (Sulem et al. (2005); Rice (2006)) can be also associated to chemical effects such as dehydration of minerals or decomposition of carbonates, theoretically studied recently by Brantut et al. (2010, 2011); Sulem and Famin (2009); Veveakis et al. (2010) and reported to take place in real faults (Hirono et al. (2007)) and experiments at laboratory conditions (Han et al. (2007); Ferri et al. (2010); Brantut et al. (2011a); De Paola et al. (2011)).

In a recent paper, Sulem et al. (2011) have shown that by resorting to a Cosserat continuum (Vardoulakis and Sulem (1995)) for describing the kinetics of a granular material, a preferred wave length for the instability mode of a layer under shear can be selected. They showed that instability can occur even in the hardening regime of the stress-strain curve, due to thermal pressurization, confirming the claim that thermal in origin mechanisms play a major role in the formation and evolution of the PSZ. The localizing structures obtained were comparable in thickness with the ones observed in nature, rationalizing thus the viscous and second gradient regularization initially proposed by Vardoulakis $(1985,1986,1996)$ for regularizing these type 
of problems. In this work we extend this analysis by including chemical reactions that may take place inside a rapidly deformed shear-band and study the impact of certain decomposition reactions to the dynamic weakening and localization of deformation in granular media.

\section{Problem Formulation}

In classical Continuum mechanics, where the continuum is allowed only for translational degrees of freedom (displacements), one may be able to predict the onset of a shear band (Rudnicki and Rice (1975)). However it can be shown that the instability tends to localize in a strip of zero thickness. Classical theories are thus unable to simulate the localization of the deformation in a shear band of finite thickness. This drawback can be traced back to the fact that conventional constitutive models do not contain material parameters with dimension of length which can scale the shear band thickness (internal length).

Thus, a fault is usually modelled as a discontinuity surface for the velocity fields. Such an oversimplifying assumption however would overestimate significantly the heat produced in a fault, and thus the temperature (as shown by Rice (2006)), imposing difficulties in our effort to determine the processes taking place during dynamic weakening of faults. To raise this discrepancy, the introduction of a thin but finite-in-width slipping zone of intense shear is requested. Vardoulakis $(1985,1986,1996)$ showed that introducing viscous (rate-dependent) considerations, combined with second gradient plasticity models, may alleviate the ill-posedness of the problem. Later, Veveakis et al. (2010) showed that indeed non-linear viscous responses provide the necessary 
counterbalancing effect to stabilize the problem of simple shear.

Early approaches by Hill (1962) and Mandel (1966) envisioned such a structure with width $d$, which however could only be artificially imposed, since -as said before- in classical continua $d$ is undetermined. It seemed as if the solutions obtained from classical continua correspond to the limit $d \rightarrow 0$ of a corresponding higher grade extension of it (see Vardoulakis and Sulem (1995), p. 268 for a comprehensive discussion). Following this conclusion, as well as experimental observation of the influence of the effect of particle irregularities and rotations inside the shear bands, Muhlhaus and Vardoulakis (1987) resorted to concepts from Cosserat Continuum mechanics to naturally determine $d$. Thus, by allowing both particle displacements and particle rotations, they accounted for the angularities of the grains, and enriched the classical continuum with additional kinematic and static fields, and calculated for sands that $d \sim 16 d_{50}$. Other mechanisms leading to localization, and initially neglected by Muhlhaus and Vardoulakis (1987), are reported to be flash heating and powder lubrication (Di Toro et al. (2011); De Paola et al. (2011); Han et al. (2010, 2011); Tisato et al. (2011)) or grain breakage (Nguyen and Einav (2010)).

In this study we follow Muhlhaus and Vardoulakis (1987) and consider a layer of saturated granular material of thickness D that is sheared in plane strain (Fig. 2) in such a way that there is no extensional strain in the $x_{1}$ -direction and displacements $u_{1}$ and $u_{2}$ of material points vary only with $x_{2}$ (and time $t$ ). The additional rotational degree of freedom of the considered 2D Cosserat continuum is $\omega_{c}$. The grains themselves are not allowed for breakage or wear, excluding thus breakage and flash heating, since the scope 


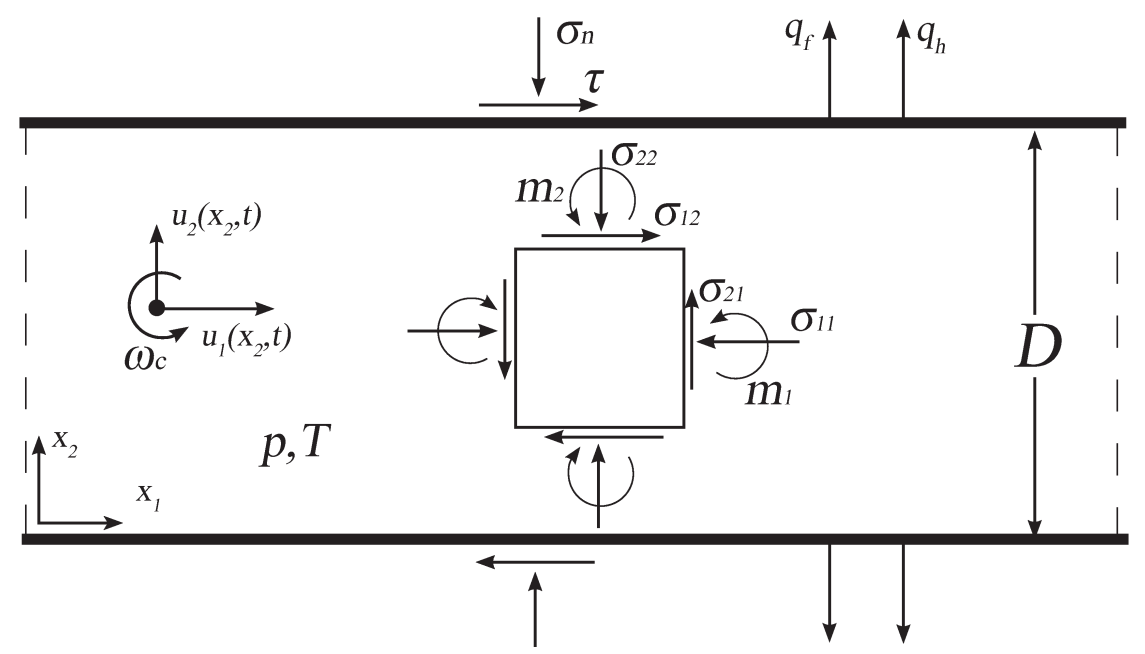

Figure 2: Problem formulation. Cosserat stresses, couple stresses and degrees of freedom.

of this study is to provide insights on the thickness of the PSZ at different temperature regimes.

\subsection{Constitutive equations of elasto-plasticity}

The incremental constitutive equations for the considered 2D Cosserat continuum are derived from the Muhlhaus - Vardoulakis plasticity model (Muhlhaus and Vardoulakis (1987)). The main feature of the model is that a 2D flow theory of plasticity for granular media with Cosserat microstructure can be derived by keeping the same definitions for the yield surface and the plastic potential as in the classical theory and by generalizing appropriately 
the stress and strain invariants involved in these definitions. The details of the model for isothermal deformation are given in Vardoulakis and Sulem (1995) and in Sulem et al. (2011). They are briefly recalled in the following.

In a two-dimensional Cosserat Continuum each material point has two translational degree of freedom $\left(v_{1}, v_{2}\right)$ and one rotational degree of freedom $\dot{\omega}_{c}$. The four components of the rate of the non-symmetric deformation tensor are given as

$$
\begin{gathered}
\dot{\epsilon}_{11}=\frac{\partial v_{1}}{\partial x_{1}} ; \dot{\epsilon}_{12}=\frac{\partial v_{1}}{\partial x_{2}}+\dot{\omega}_{c} \\
\dot{\epsilon}_{21}=\frac{\partial v_{2}}{\partial x_{1}}-\dot{\omega}_{c} ; \dot{\epsilon}_{22}=\frac{\partial v_{2}}{\partial x_{2}}
\end{gathered}
$$

and the two components of the curvature of the deformation rate (gradient of the Cosserat rotation rate)

$$
\dot{\kappa}_{1}=\frac{\partial \dot{\omega}_{c}}{\partial x_{1}} ; \dot{\kappa}_{2}=\frac{\partial \dot{\omega}_{c}}{\partial x_{2}}
$$

Moreover we decompose the stresses and strain rates into spherical and deviatoric parts, $\sigma_{i j}=s_{i j}+\sigma_{k k} \delta i j / 2$ and $\dot{\epsilon}_{i j}=\dot{e}_{i j}+\dot{\epsilon}_{k k} \delta_{i j} / 2$, where $\delta_{i j}$ is the Kronecker's delta. The following generalized stress and strain invariants are used:

$$
\begin{aligned}
\sigma & =\frac{\sigma_{i i}}{2} ; \tau=\sqrt{h_{1} s_{i j} s_{i j}+h_{2} s_{i j} s_{j i}+h_{3} m_{k} m_{k} / R} \\
\dot{\epsilon}^{p} & =\dot{\epsilon}_{k k}^{p} ; \dot{\gamma}^{p}=\sqrt{g_{1} \dot{e}_{i j}^{p} \dot{e}_{i j}^{p}+g_{2} \dot{e}_{i j}^{p} \dot{e}_{j i}^{p}+R^{2} g_{3} \dot{\kappa}_{k} \dot{\kappa}_{k}},
\end{aligned}
$$


where $h_{i}=[3 / 4,-1 / 4,1], g_{i}=[3 / 2,1 / 2,1]$ for the so-called static Cosserat model, and $R$ is the internal length (Vardoulakis and Sulem (1995)).

Besides the four components of the non-symmetric stress-tensor $\sigma_{i j}$, there are two couple stresses $m_{k}(k=1,2)$. As in classical small-strain plasticity theory, the deformation is decomposed into elastic and plastic parts

$$
\dot{\epsilon}_{i j}=\dot{\epsilon}_{i j}^{e}+\dot{\epsilon}_{i j}^{p} ; \dot{\kappa}_{k}=\dot{\kappa}_{k}^{e}+\dot{\kappa}_{k}^{p}
$$

Following Sulem et al. (2011) we assume a Terzaghi decomposition of the stress tensor in effective stress and pore pressure $\left(\sigma_{i j}=\sigma_{i j}^{\prime}-p \delta_{i j}\right)$ and assume a Coulomb yield stress and plastic potential for the effective stresses:

$$
\begin{aligned}
& F=\tau+\mu(\sigma+p), \\
& Q=\tau+\beta(\sigma+p),
\end{aligned}
$$

174 where the mobilized friction coefficient $\mu$ and the dilatancy coefficient $\beta$ are functions only of the accumulated plastic strain $\gamma^{p}$. Under these considerations, the rate thermo-poro-elasto-plastic relationships are expressed as follows

$$
\begin{array}{r}
\dot{\gamma}=\frac{\dot{\tau}}{G}+\dot{\gamma}^{p} \\
\dot{\epsilon}=\frac{1}{K}(\dot{\sigma}+\dot{p})+\alpha_{s} \dot{T}+\dot{\epsilon}^{p}
\end{array}
$$

178 where $G$ and $K$ are the elastic shear and bulk modulus respectively, $\alpha_{s}$ the thermal dilation coefficient of the solid skeleton and $T$ the temperature. The 
rate of plastic deformation is written as

$$
\dot{\gamma}^{p}=\frac{1}{H}[\dot{\tau}+\mu(\dot{\sigma}+\dot{p})] ; \dot{\epsilon}^{p}=\beta \dot{\gamma}^{p},
$$

where $H=H\left(\gamma^{p}\right)=h(\sigma+p)$ (with $\left.h=d \mu / d \gamma^{p}\right)$ is the plastic hardening modulus, which is related to the tangent modulus $H_{\tan }$ of the $\tau$ versus $\gamma$ curve through the relationship $H_{t a n}=\frac{H}{1+H / G}$ and is either positive or negative according to whether the $\tau-\gamma$ curve is increasing (hardening) or decreasing (softening). Notice that, in principle $H_{t a n}$ is varying with strain, as thoroughly presented by Rudnicki and Rice (1975). When $H_{\text {tan }}$ is non positive then the material is enterring an unstable regime, where softening induces localization of deformation in a shear band (Holcomb and Rudnicki (2001)). However, when the material is fluid saturated (Sulem et al. (2011)), thermal pressurization may cause localization of deformation even at hardening regimes, before reaching $H_{t a n}=0$, where the material is supposed to be stable. In this work we study the effect of a chemical reaction at high temperatures, near the activation temperature of the reaction, to assess whether the reaction itself may induce softening and localization at even higher values of the hardening modulus. 


\subsection{Stress Equilibrium}

For the considered 2D Cosserat continuum and the configuration of Fig. 2 , the local equilibrium equations are

$$
\begin{aligned}
\frac{\partial \sigma_{12}}{\partial x_{2}} & =0, \\
\frac{\partial \sigma_{22}}{\partial x_{2}} & =0, \\
\frac{\partial m}{\partial x_{2}}+\sigma_{21}-\sigma_{12} & =0
\end{aligned}
$$

where $m=m_{2}$ and $m_{1}=0$. The stresses applied at the boundary are a shear stress $\tau$ and a normal stress $\sigma_{n}$ in the $x_{2}$ direction. It is assumed that no couple stress is imposed at the boundary. Prior to localization, the state of stress and strain is uniform and considering the couple free boundary condition, the couple stress is identically zero in the sheared layer. Therefore the rock behaves as a classical continuum before localization.

\subsection{Reaction kinetics}

We assume the presence of a decomposition reaction that decomposes the solid skeleton and produces excess pore fluid. In particular, as an example we consider the reaction of calcite decomposition $\left(\mathrm{CaCO}_{3} \rightarrow \mathrm{CaO}+\mathrm{CO}_{2}\right)$, producing $\mathrm{CO}_{2}$ which at high pressures and temperatures (conditions similar to the ones met in faults at depth) is at supercritical, liquid state (Sulem and Famin (2009)). Evidence of the presence of this reaction in faults is found in many active crustal faults (Famin et al. (2008)), and experimentally reproduced for example by Han et al. (2007) from experiments on simulated 
faults in Carrara marble. Other types of chemical reactions such as mineral dehydration (Brantut et al. (2011)) could be studied following the same methodology.

Following Sulem and Famin (2009) and Veveakis et al. (2010), we assume that the reaction is taking place with a rate $r$, which on its turn can be expressed from first order reaction kinetics as (Law (2006))

$$
r \approx \frac{\rho_{s}}{M_{\mathrm{CaCO}_{3}}} A_{0} e^{-T_{c} / T},
$$

where $T_{c}=E / R_{a}$ the activation temperature of the reaction, $E$ the activation energy and $R_{a}$ the universal gas constant. In this expression $A_{0}$ is the preexponential factor, a parameter that may vary significantly, obtaining for calcite decomposition values between $10^{2} s^{-1}$ and $10^{20} s^{-1}$ (Lvov et al. (2002)).

The Arrhenius model assumed in Eq. (9), is the simplest one, but has received much criticism for its validity, mainly due to the strongly varying magnitudes of both $A_{0}$ and $T_{c}$ for a given reaction (Lvov et al. (2002)). In the pertinent literature there are numerous models suggested to replace it (Law (2006), pp. 67-72) for evaluating the reaction rate of a decomposition reaction. Lvov et al. (2002) provide a comprehensive literature guide through the models used, along with experimental data for calcite decomposition. Even for this well reported reaction, the production rates are measured through experiments at zero or very low pressures, of the order of mbar. Nonetheless it is known that pressure reduces significantly the rate of a reaction (Lvov (2007), pp. 79), hence when applying to geomechanical problems, one would need experimental data of calcite decomposition at pressures of the order of several tens of $M P a$. To our knowledge, such information is not available in the literature. 
Apart from the pressure dependency of the production rates, we need to emphasize that the activation energy of a reaction also varies with grain size and the deformation history of a material. In the case of calcite, when the grain size decreases from $2-5$ micron to $40 \mathrm{~nm}$ (a grain size typically found in high speed experiments performed on limestones (Tisato et al. (2011); Han et al. (2007, 2011); De Paola et al. (2011)), the activation energy for the reaction decreases from $200 \mathrm{~kJ} / \mathrm{mol}$ to $130 \mathrm{~kJ} / \mathrm{mol}$ (see Table 1 in Yue et al (1999)), even without plastic deformation of the particles. Thus, $T_{c}$ could be temperature dependent on itself, correlating the nanoparticles produced with the chemical reaction (due to chemical precipitation, Yue et al (1999)), unlike the plastically deformed nanoparticles produced in high speed experiments. The internal plastic deformation induced by milling during frictional sliding might further reduce the activation energy of the reaction (Fisher. (1988)). Hence, emphasis should be given on thorough experimental detemination of the reaction parameters at various temperature and pressure regimes.

\subsection{Fluid-mass Conservation}

Following the decomposition of the plastic strain rates into elastic and plastic parts (Eq. 4), we consider the volumetric plastic strain rate to consist of a mechanical part $\dot{\epsilon}_{m}^{p}$ subject to the constitutive behavior of Eq. 7 and a chemical part $\dot{\epsilon}_{c}^{p}$, influenced by the reaction rate $r$

$$
\dot{\epsilon}^{p}=\dot{\epsilon}_{m}^{p}+\dot{\epsilon}_{c}^{p}
$$

Under the above considerations and by assuming that the solid matrix is plastically incompressible, the diffusion-reaction equation for the pore pressure 
is obtained from the fluid mass equation as (Sulem and Famin (2009))

$$
\frac{\partial p}{\partial t}=c_{h y} \frac{\partial^{2} p}{\partial x_{2}^{2}}+\Lambda \frac{\partial T}{\partial t}-\frac{\beta}{\beta^{\star}} \frac{\partial \dot{\gamma}^{p}}{\partial t}+\frac{\rho_{s}-\rho_{f} \zeta}{\rho_{f} \beta^{\star}} \frac{A_{0}}{M_{\mathrm{CaCO}_{3}}} e^{-T_{c} / T}
$$

where $\zeta=\frac{M_{\mathrm{CaCO}_{3}}}{M_{\mathrm{CO}_{2}}}-\frac{\rho_{\mathrm{CaCO}_{3}}}{\rho_{\mathrm{CaO}}} \frac{M_{\mathrm{CaO}}}{M_{\mathrm{CO}_{2}}}, \rho_{i}$ the density of the $i$-th constituent and $\rho_{s}$ the density of the solid skeleton, $c_{h y}$ the hydraulic diffusivity, $\beta^{\star}$ the storage capacity and $\Lambda=\left(\lambda_{f}-\lambda_{n}\right) / \beta^{\star}$ the pressurization coefficient, expressed as the difference of the thermal expansion coefficimobilizedents of the fluid $\left(\lambda_{f}\right)$ and the pore volume $\left(\lambda_{n}\right)$.

\subsection{Heat Equation}

By assuming that all the mechanical work input is converted into heat (Chester et al. (2005); Pittarello et al. (2008)), and that the heat is expressed through Fourier's law, we may obtain the diffusion-reaction temperature equation (Sulem and Famin (2009); Veveakis et al. (2010))

$$
\frac{\partial T}{\partial t}=c_{t h} \frac{\partial^{2} T}{\partial x_{2}^{2}}+\frac{1}{\rho C} \tau \dot{\gamma}^{p}-\frac{|\Delta H|}{\rho C} \frac{\rho_{s}}{M_{\mathrm{CaCO}_{3}}} A_{0} e^{-T_{c} / T},
$$

where $c_{t h}$ is the thermal diffusivity, $\rho C$ the specific heat capacity of the mixture and $|\Delta H| \approx E$ the specific enthalpy of the reaction, expressing the energy consumed during an endothermic reaction.

\section{Undrained-adiabatic limit}

The first approximation in our effort to assess the influence of these weakening mechanisms during earthquake slip is to prohibit drainage and heat flux at the boundaries of the layer $\left(q_{f}=q_{h}=0\right)$. This case corresponds to the well known undrained-adiabatic limit, acknowledged to be established at or 
near seismic rates, i.e. when the heat production rate and pore pressure increase in the slipping zone is significantly larger than the heat and pore pressure diffusion times towards the fault core and in the damage zone (Garagash and Rudnicki. (2003a,b)). It provides a first insight on the impact of each mechanism on the dynamic weakening of faults. The actual value of heating rate required for the onset of the weakening mechanisms varies with the material of the fault gouge (Di Toro et al. (2011)).

In addition to the above, we assume that the normal stress $\sigma_{n}$ acting on the sheared layer is constant. From Eqs. (7),(11),(12) we may obtain the following relationship between the shear stress rate, the strain rate and the temperature rate:

$$
\dot{\tau}=\frac{\bar{H}}{1+\bar{H} / G} \dot{\gamma}+\frac{\bar{B}}{1+\bar{H} / G} \dot{T}
$$

where

$$
\begin{array}{r}
\bar{H}=H+\mu \frac{\beta}{\beta^{\star}}-\mu \tau\left(\frac{1}{\beta^{\star}|\Delta H|} \frac{\rho_{s}-\zeta \rho_{f}}{\rho_{f}}\right), \\
\bar{B}=\mu\left(\frac{\rho C}{\beta^{\star}|\Delta H|} \frac{\rho_{s}-\zeta \rho_{f}}{\rho_{f}}-\Lambda\right) .
\end{array}
$$

Obviously, when the thermal effects are neglected (i.e. in the absence of thermal pressurization and chemical reaction) and incompressible solid and fluid are assumed (so that $\beta^{\star}=1 / K$ ) the classical expression for dilatant hardening effect, as proposed by Rice (1975) is retrieved

$$
\dot{\tau}=\frac{H+\mu \beta K}{1+(H+\mu \beta K) / G} \dot{\gamma}
$$

For dilatant material $(\beta>0)$ we may recognize in $(13)$ a hardening effect due to dilatancy with the term $\mu \beta / \beta^{\star}$ and a strong softening effect from the 
reaction due to the term $\frac{\mu \tau}{\beta^{\star}}\left(\frac{\rho_{s}-\zeta \rho_{f}}{\rho_{f}|\Delta H|}\right)$ (positive for calcite decomposition, as shown by Sulem and Famin (2009)).

As shown by Sulem et al. (2011), in the absence of a chemical reaction instability may occur even in the hardening regime of the $\tau-\gamma$ curve $(H>0)$ if the dilatancy effect is very weak (as it is the case at great depth) and if the thermal pressurization effect is significant. Here we verify this claim and indicate that the presence of a chemical reaction may lead to instability at even higher hardening regimes.

\section{Linear Stability Analysis of undrained adiabatic shearing of a Cosserat layer}

At any given state, the evolution time of the kinematic quantities, the pore fluid pressure and the temperature determine the stability of the shearing of the Cosserat layer. The small perturbations considered herein are defined as follows:

$$
\begin{gathered}
u_{1}\left(x_{2}, t\right)=u_{1}^{0}\left(x_{2}, t\right)+\tilde{u}_{1}\left(x_{2}, t\right), \\
u_{2}\left(x_{2}, t\right)=u_{2}^{0}\left(x_{2}, t\right)+\tilde{u}_{2}\left(x_{2}, t\right), \\
\omega_{c}\left(x_{2}, t\right)=\omega_{c}^{0}\left(x_{2}, t\right)+\tilde{\omega}_{c}\left(x_{2}, t\right), \\
p\left(x_{2}, t\right)=p^{0}\left(x_{2}, t\right)+\tilde{p}\left(x_{2}, t\right), \\
T\left(x_{2}, t\right)=T^{0}\left(x_{2}, t\right)+\tilde{T}\left(x_{2}, t\right) .
\end{gathered}
$$

${ }_{311}$ The governing equations for the perturbed fields $\left(\tilde{u}_{1}, \tilde{u}_{2}, \tilde{\omega}_{c}, \tilde{p}, \tilde{T}\right)$ are of

the same form as the ones derived in the previous section. Similarly, the fluid 
and heat fluxes are prevented at the boundaries of the layer. However, the internal fluid and heat flows are permitted inside the layer.

\subsection{Normalized equations}

The system of equations can be brought in a dimensionless form by introducing the dimensionless quantities:

$$
\begin{array}{r}
x=\frac{x_{1}}{R}, z=\frac{x_{2}}{R}, \bar{u}_{i}=\frac{u_{i}}{R}, \\
\bar{p}=\frac{p}{\sigma_{n}}, \bar{\sigma}_{i j}=\frac{\sigma_{i j}}{\sigma_{n}}, \bar{t}=\frac{c_{t h}}{R^{2}} t, \bar{T}=\frac{\Lambda}{\sigma_{n}} T
\end{array}
$$

where $R$ is the internal length of the Cosserat model, which can be related to the mean grain size $R=d_{50} / 2$. The linearized forms of the pore pressure and heat equation (linearized around $T^{0}=T_{c}$, i.e. at higher temperature regimes, near the activation temperature of the reaction) may be reduced in their dimensionless forms as (the superimposed bars are omitted for convenience):

$$
\begin{array}{r}
\frac{\partial p}{\partial t}=\eta \frac{\partial^{2} p}{\partial z^{2}}+\frac{\partial T}{\partial t}+\delta \frac{\partial \dot{\gamma}^{p}}{\partial t}+\chi \frac{T-T_{c}}{T_{c}}, \\
\frac{\partial T}{\partial t}=\frac{\partial^{2} T}{\partial z^{2}}+\alpha \frac{\partial \dot{\gamma}^{p}}{\partial t}-\psi \frac{T-T_{c}}{T_{c}}
\end{array}
$$

where

$$
\begin{array}{r}
\eta=\frac{c_{h y}}{c_{t h}}, \delta=\frac{\beta}{\beta^{\star} \sigma_{n}}, \alpha=\frac{\Lambda \tau_{0}}{\rho C \sigma_{n}} \\
\chi=\frac{\rho_{s}-\zeta \rho_{f}}{\rho_{f} \beta^{\star}} \frac{R^{2}}{\Lambda c_{t h}} A_{0} \\
\psi=\frac{\rho_{s} \Delta H}{\rho C M_{C a C O_{3}}} \frac{R^{2}}{c_{t h}} \frac{\Lambda}{\sigma_{n}} A_{0},
\end{array}
$$


324

$$
\begin{array}{r}
\frac{\partial \gamma^{p}}{\partial t}=\frac{1}{H^{\star}}\left[\frac{\partial \sigma_{12}}{\partial t}+\frac{\sigma_{21}}{\partial t}+\mu\left(\frac{\sigma_{11}^{\prime}}{\partial t}\right)+\frac{\sigma_{22}^{\prime}}{\partial t}\right], \\
H^{\star}=\frac{H}{\sigma_{n}}=h \frac{\sigma^{\prime}}{\sigma_{n}} .
\end{array}
$$

and

The corresponding dimensionless form of the linear and angular momentum with inertia and micro-inertia terms is as follows:

$$
\begin{aligned}
\frac{\partial \sigma_{12}}{\partial z}-I \frac{\partial^{2} u_{1}}{\partial t^{2}} & =0 \\
\frac{\partial \sigma_{22}^{\prime}}{\partial z}-\frac{\partial p}{\partial z}-I \frac{\partial^{2} u_{2}}{\partial t^{2}} & =0 \\
\frac{\partial m}{\partial z}+\sigma_{21}-\sigma_{12}-\frac{I}{2} \frac{\partial^{2} \omega_{c}}{\partial t^{2}} & =0
\end{aligned}
$$

227 where $I=\frac{c_{t h}^{2} \rho_{s}}{R^{2} \sigma_{n}}$ and the expressions of the stresses and couple stresses are derived from the elastoplastic model presented in Section 2.1 (Sulem et al. (2011))

Following Vardoulakis and Sulem (1995) and Sulem et al. (2011), we introduce the perturbed fields (16) for a given initial configuration, and the spatial dependency of the perturbations is decomposed into Fourier modes with wavelength $\lambda$. Hence we introduce perturbations of the form

$$
\begin{gathered}
\tilde{u}_{1}\left(x_{2}, t\right)=U_{1} e^{s t} \sin \left(\frac{z}{\lambda}\right), \\
\tilde{u}_{2}\left(x_{2}, t\right)=U_{2} e^{s t} \sin \left(\frac{z}{\lambda}\right), \\
\tilde{\omega}_{c}\left(x_{2}, t\right)=\Omega e^{s t} \cos \left(\frac{z}{\lambda}\right), \\
\tilde{p}\left(x_{2}, t\right)=\Pi e^{s t} \cos \left(\frac{z}{\lambda}\right), \\
\tilde{T}\left(x_{2}, t\right)=\Theta e^{s t} \cos \left(\frac{z}{\lambda}\right),
\end{gathered}
$$


with $\lambda=D /(\pi N R)$ and $N$ equal to an integer satisfying the zero heat and fluid flux boundary conditions at $z=\frac{x_{2}}{R}=0$. By substituting the perturbation fields (22) into the linearized governing equations $(18,21)$, we obtain a homogeneous algebraic system for the coefficients $U_{1}, U_{2}, \Omega, \Pi, \Theta$. A nonzero solution is possible only when the determinant of the linear system vanishes. This request results in a characteristic polynomial equation of degree 8 for the growth coefficient $s$. If a root has a positive real part, then the corresponding perturbation grows exponentially in time.

\subsection{Numerical example}

We consider the case of a 7- $\mathrm{km}$ deep fault, of a calcite-made gouge material having the parameters depicted in Table 4.2. With these values, and by performing the method presented in the Appendix A, we obtain a critical value for the hardening modulus $h_{c r} \approx 6$, such that for $h \geq h_{c r}$ all the roots of the polynomial equation have negative real part, and thus the system is stable. For $h<h_{c r}$ roots with positive real parts exist, bringing the system to instability.

We observe that the destabilizing effect of the chemical reaction by the fact that instability can occur in the hardening regime, for values of the hardening modulus significantly larger than in the case of thermal pressurization, $h_{c r}^{\prime}=0.014$ (Sulem et al. (2011)). Hence, as temperature increases reaching the activation temperature of the reaction, the material becomes unstable even at regimes mechanically considered as stable in the absence of chemical reaction.

In order to assess the localizing effect of the chemical reaction, we plot in the Appendix A the greatest root (i.e. the one corresponding to the insta- 


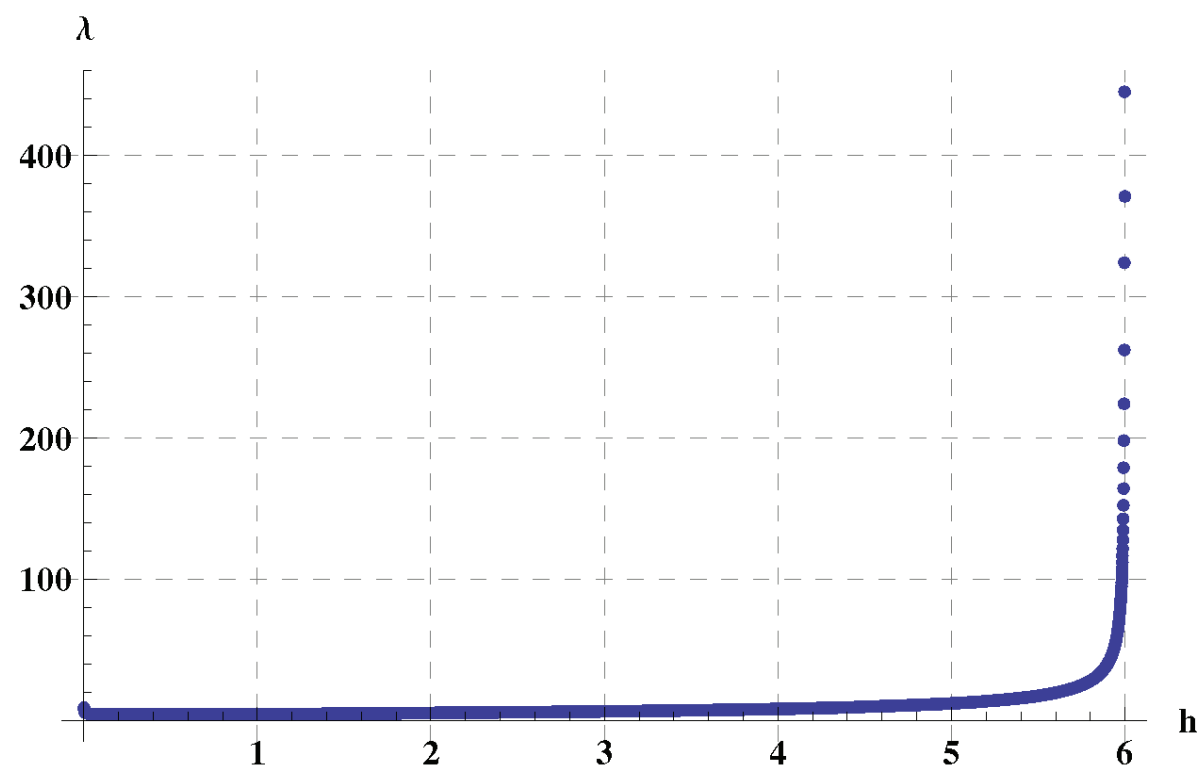

$\lambda$

(a)

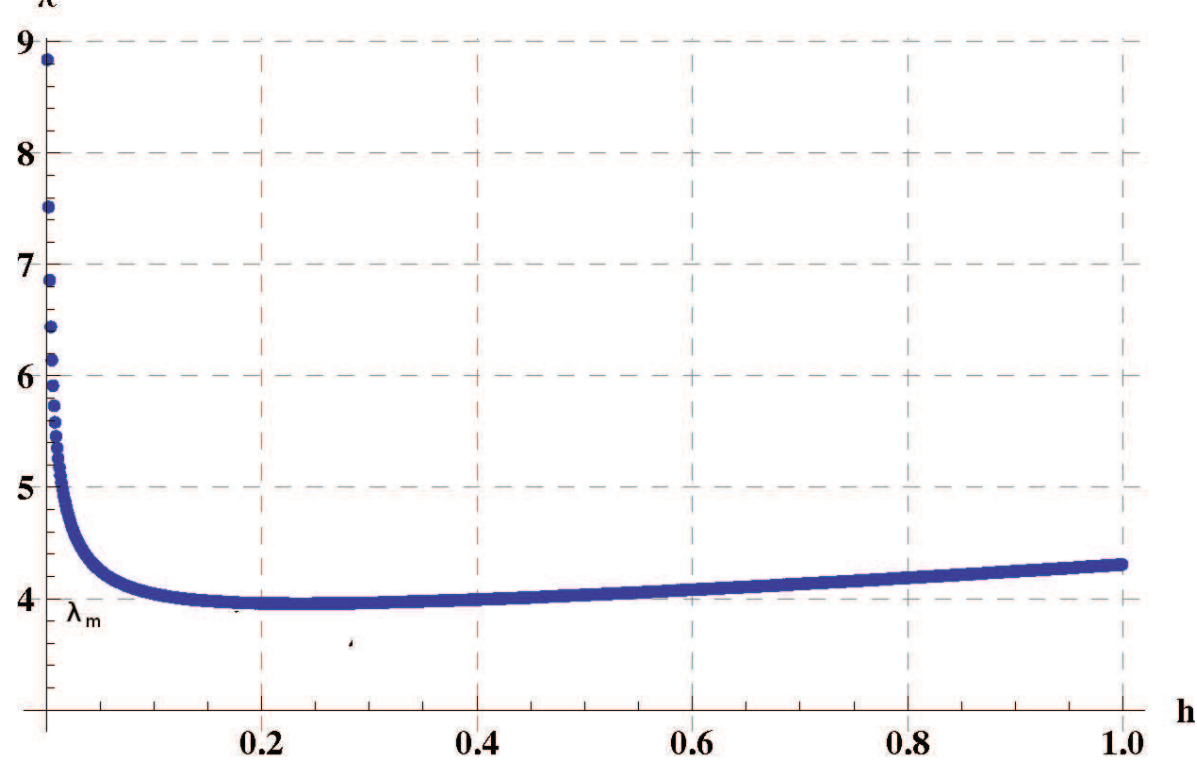

(b)

Figure 3: (a) Wave length $\lambda$ corresponding to the fastest growth coefficient of the instability versus the hardening modulus $h$. (b) The same as in (a), focused in the area $0<h<1$, where the selected (minimum) wavelength, $\lambda_{m}$, is located. The results are calculated for $A_{0}=10^{6}$. 


\begin{tabular}{cccccc}
\hline \hline Parameter & Value & Units & Parameter & Value & Units \\
\hline$\phi_{0}$ & 0.03 & - & $c_{h y}$ & $10^{-5}$ & $\mathrm{~m}^{2} / \mathrm{s}$ \\
$\sigma_{n}^{\prime}$ & 200 & $\mathrm{MPa}$ & $c_{t h}$ & $10^{-6}$ & $\mathrm{~m}^{2} / \mathrm{s}$ \\
$M_{\mathrm{CaCO} 3}$ & 0.1 & $\mathrm{~kg} / \mathrm{mol}$ & $R$ & 0.1 & $\mathrm{~mm}$ \\
$M_{\mathrm{CaO}}$ & 0.056 & $\mathrm{~kg} / \mathrm{mol}$ & $\mathrm{G}$ & $10^{4}$ & $\mathrm{MPa}$ \\
$M_{\mathrm{CO}}$ & 0.044 & $\mathrm{~kg} / \mathrm{mol}$ & $K$ & $2 \cdot 10^{4}$ & $\mathrm{MPa}$ \\
$\rho_{s}$ & $2.5 \cdot 10^{3}$ & $\mathrm{~kg} / \mathrm{m}^{3}$ & $\mu$ & 0.5 & - \\
$\rho_{f}$ & $10^{3}$ & $\mathrm{~kg} / \mathrm{m}^{3}$ & $\beta$ & 0 & - \\
$\rho C$ & 2.8 & $\mathrm{MPa} /{ }^{\circ} \mathrm{C}$ & $A_{0}$ & $10^{6}$ & $1 / \mathrm{s}$ \\
$\Lambda$ & 0.5 & $\mathrm{MPa} /{ }^{\circ} \mathrm{C}$ & $|\Delta H|$ & 200 & $\mathrm{~kJ} / \mathrm{mol}$ \\
\hline
\end{tabular}

Table 1: Indicative material parameters for a fault at $7 \mathrm{~km}$ depth, where the initial temperature is about $200^{\circ} \mathrm{C}$. For these values of the parameters and for $T_{c}=800^{\circ} \mathrm{C}$ the corresponding dimensionles groups are $\zeta=1.24, \alpha=0.06, \delta=0, \eta=10, I=1.25 \cdot 10^{-9}$, $\bar{\alpha}_{s}=10^{-2}, \chi \approx 2 A_{0}=2 \cdot 10^{6}, \psi \approx 0.01 A_{0}=10^{4}$

bility mode with the fastest growth in time) as a function of the wavelength $\lambda$ (Figure 6b) and select the wavelength number $\lambda=\lambda_{m}$ corresponding to the maximum value of the growth coeffcient $s$, so that a wavelength with the fastest growth in time appears. In Figure 3 this selected wavelength is plotted against the hardening modulus. As in Sulem et al. (2011) the selected wavelength tends to infinity for $h \rightarrow h_{c r}^{-}$denoting that at initial instability no localization takes place. As the hardening modulus decreases the wavelength decreases as well, reaching a minimum at $h \approx 0.16$, where 
$\lambda_{m} \approx$ 3.95. Muhlhaus and Vardoulakis (1987) similarly obtained that at the bifurcation state the shear-band thickness for dry granular materials is infinite and decreases beyond the bifurcation state as the strain localization process evolves.

We notice that the selected wavelength $\left(\lambda_{m} \approx 3.95\right)$ in this case is significantly smaller than in the absence of the chemical reaction $\left(\lambda_{m}^{\prime} \approx 187\right)$, revealing the crucial, localizing role of the chemical reaction. Since for this example we have used indicative values for the reaction parameters, like the pre-exponential factor and the activation temperature, we proceed with an analysis of these parameters in order to reveal their influence on the width of the PSZ and the type of instability.

\section{Parametric Analysis. Impact of the chemical reaction and the pressurization mechanism}

From the parameters appearing in 4.2, those being less constrained in values are the parameters of the reaction $A_{0}$ and $T_{c}$. Since they always appear in the parameter groups as a ratio $A_{0} / T_{c}$, we emphasize on the influence of this ratio on the stability of the system by treating it as a parameter.

\subsection{Effect of the chemical reaction}

To assess the influence of the chemical reaction, we plot in Figure 4 the values of $h_{c r}$ with the ratio of the reaction parameters $\frac{A_{0}}{T_{c}}$ varying from $10^{-4}$ to $10^{12}$. We observe that as $\frac{A_{0}}{T_{c}} \rightarrow 0$, then $h_{c r} \rightarrow h_{c r}^{\prime}=0.014$, thus it tends to the case of pressurization alone as weakening mechanism (Sulem et al. (2011)). As $\frac{A_{0}}{T_{c}}$ increases, $h_{c r}$ increases as well, reaching an upper threshold at $h_{c r}^{m} \approx 6$. 


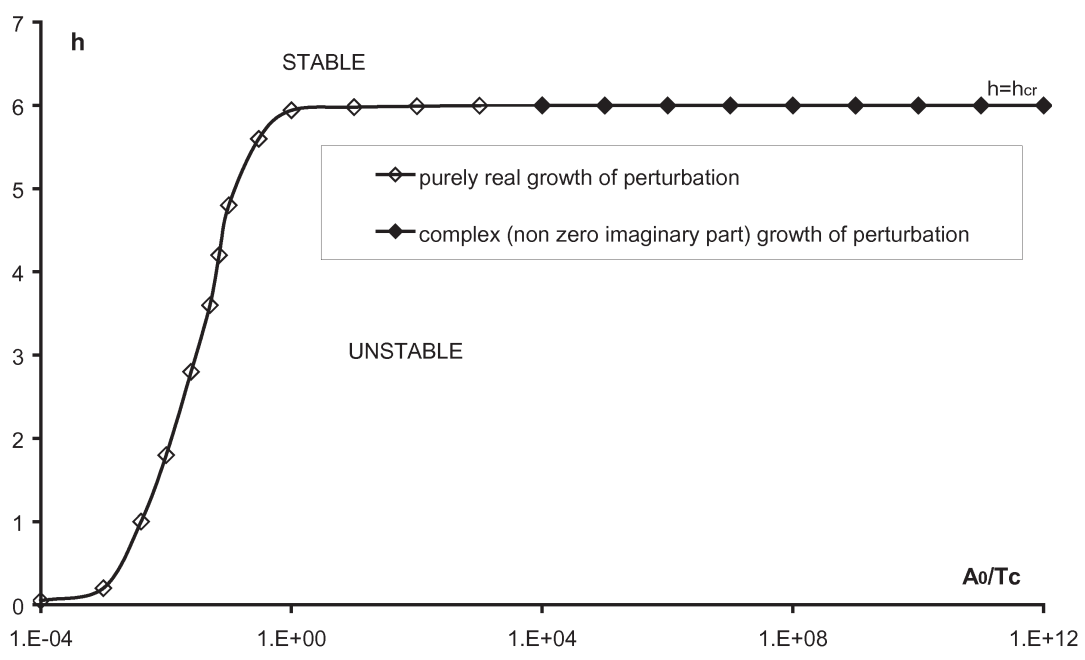

Figure 4: The critical hardening modulus $h_{c r}$ as a function of $A_{0} / T_{c}$ (logarithmic scale for $\left.A_{0} / T_{c}\right)$. 
It is to be noted that as soon as $h_{c r}$ reaches $h_{c r}^{m}$, then the maximum positive root changes from purely real to complex (Figure 4). This effect takes place at a critical $\frac{A_{0}}{T_{c}}$ (in this case $A_{0}^{c r}=10^{7} \mathrm{~s}^{-1}$ for $T_{c}=800^{\circ} \mathrm{C}$ ) and signifies the onset of oscillatory instabilities due to the chemical reaction. The existence of oscillatory instabilities is questionable because when the temperature decreases below the given threshold the reaction stops. In other words, the linear stability analysis is not valid for non monotonous processes in case of non-linear behaviour. For this reason the exact type of these oscillatory instabilities, as well as their time evolution cannot be determined by the present linear stability analysis. To this end nonlinear analyses and time integration of the full system of equations is required, to determine whether imaginary eigenvalues may correspond to stick-slip type of instability (appearing as limit cycles on a phase diagram, as for example in Alevizos and Veveakis (2011))

\subsection{Effect of thermal pressurization mechanism}

As already mentioned and anticipated, when $\frac{A_{0}}{T_{c}} \rightarrow 0$, then $h_{c r} \rightarrow h_{c r}^{\prime}=$ 0.014 , thus the system is influenced by pressurization alone as weakening mechanism (Sulem et al. (2011)). However, when the reaction becomes strong and $\frac{A_{0}}{T_{c}}$ increases so that $h_{c r} \rightarrow h_{c r}^{m}$, the effect of thermal pressurization, compared to the chemical effect (i.e. the production of excess pore fluid due to $\mathrm{CaCO}_{3}$ lattice breakdown and $\mathrm{CO}_{2}$ production), is negligible. This fact becomes apparent in the Appendix A, where we compare the $s-\lambda$ curves of Figures $7 \mathrm{~b}$ and $6 \mathrm{~b}$ with the corresponding ones in the absence of thermal pressurization, appearing in Figure 8.

We notice that the same response is obtained, both for the magnitudes of 
$h, s$ and $\lambda$ and for the type of instability (nodal instability for $A_{0}=10^{6} s^{-1}$ and oscillatory for $A_{0}=10^{7} \mathrm{~s}^{-1}, T_{c}=800^{\circ} \mathrm{C}$ ). The pre-exponential factor for the considered depths cannot be realistically estimated, since it is pressure dependent (Lvov et al. (2002)) and there is a lack of experimental data at high pressures, however usually it is accepted to be more than $10^{10} \mathrm{~s}^{-1}$ (for example Dollimore et al. (1996) suggest a value of the order of $10^{15} \mathrm{~s}^{-1}$, used also by Sulem and Famin (2009)). Thus, we may conclude that at high temperatures where reaction is triggered (around $T_{c}$ ), and for the decomposition reaction considered, the main weakening mechanism of the two is the reaction, verifying the recent experimental findings of Han et al. (2007) and Ferri et al. (2010). However, as also discussed by Han et al. (2010) and De Paola et al. (2011) important weakening mechanisms like powder lubrication and flash heating (see also Rice (2006)) should not be excluded if one would like to model all the mechano-physical processes taking place in a fault, since they could have equal or even more dramatic role than chemical pressurization. In addition secondary chemo-mechanical effects like the breakdown of calcite grains expressed through the production of holes in the Calcite grains due to decarbonation reduce also the compressive strength, forcing the microstructure to collapse. In this study we have excluded these mechanisms to emphasize on the two pressurization mechanisms, i.e. thermal and chemical pressurization.

However, we notice that the initial temperature for a $7-\mathrm{km}$ fault is around $200^{\circ} \mathrm{C}$, far below the activation temperature $T_{c} \approx 800^{\circ} \mathrm{C}$ of calcite decomposition. Up to the temperature regime around $T_{c}$ the reaction term is negligible and localization is driven by thermal pressurization, a fact that could not 
be analyzed in this study due to the choice of the reference temperature $T_{c}$, around which we linearized in Section 4.1, in order to emphasize on the reaction itself. As temperature increases the process is progressively localizing towards an ultimate shear-zone whose thickness is determined by the reaction itself. To address this claim, we proceed with a shear band thickness analysis.

\subsection{Shear band thickness, Wavelength selection}

Indeed, it is expected that at temperatures near $T_{c}$ the width $D$ of the PSZ of Fig.1 is influenced by the chemical reaction. To verify this claim we may plot the minimum selected wavelength against the ratio $A_{0} / T_{c}$ (Figure $5)$ to conclude that with increasing $A_{0} / T_{c}, \lambda_{m}$ and thus $D$ decrease. In the absence of chemical reaction, $\lambda_{m}$ was calculated to be equal to about 187 . The ultimate value for $\lambda_{m}$ in the presence of a chemical reaction is around 3, denoting that the PSZ may be an extremely localized structure, obtaining $\lambda_{m}=300 \mu \mathrm{m}$ when $d_{50}=0.1 \mathrm{~mm}$ as is the case for fine sands, or even less if we consider possible average grain sizes from principal slipping zones, up to $10 \mu m$, in the lines of the field evidence provided by Smith et al (2011) and thoroughly discussed in the introduction.

Thus, indeed the onset of the reaction is taking place in an ultra localized zone, that could be significantly thinner than the initial one defined by thermal pressurization alone $\left(\lambda_{m} \sim 187\right)$. This means that in a "nonreactive" fault thermal pressurization of pore fluids would result in a slipping zone of $18.7 \mathrm{~mm}$ thick (for a fault material with $d_{50}=0.1 \mathrm{~mm}$ ), while under the same ambient conditions and slip rate, in a "reactive" gouge (e.g., calcite) chemical reaction would result in a slipping zone of $0.3 \mathrm{~mm}$. 


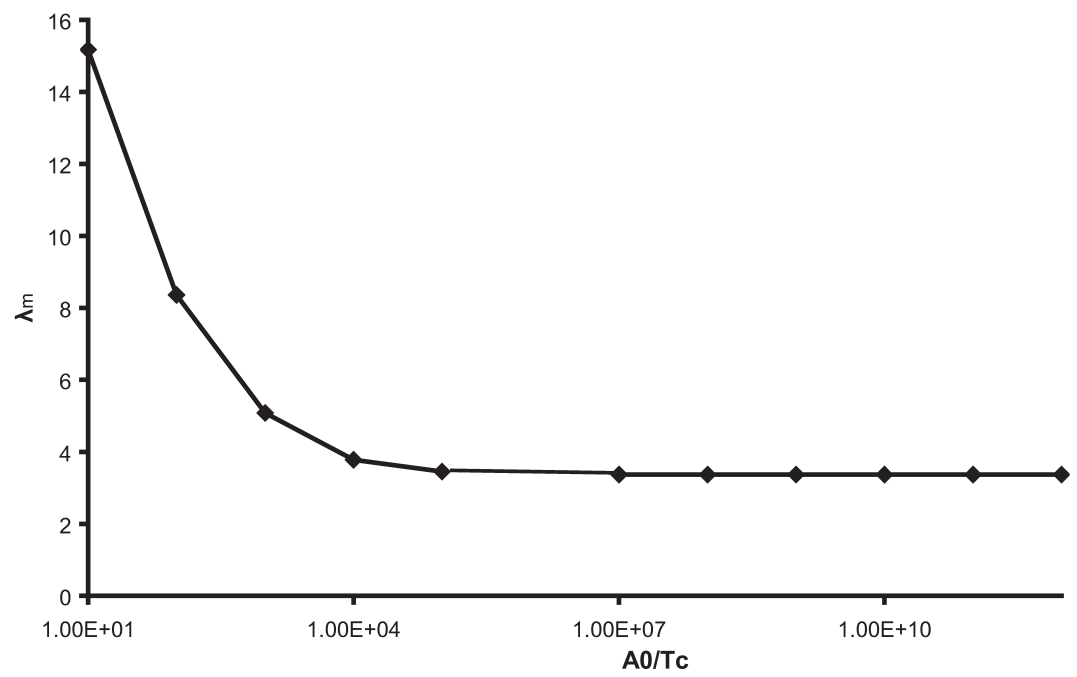

Figure 5: The selected wavelength $\lambda_{m}$ as a function of $A_{0} / T_{c}$ 
What have to be noted at this point, is that localizing mechanisms like flash heating and breakage have been neglected in this study, as discussed thoroughly in Sections 2 and 5.2. Including these mechanisms would provide a more realistic behaviour of the fault even at low temperatures where pressurization or the chemical reaction are absent. In addition, the thickness of this ultimate structure (the PSZ) seems to push continuum theories to its limits, since the width of the structure is comparable to the size of the average grain. However, we emphasize that in this study the average grain size used $\left(d_{50}\right)$ is the one of the initial grain size distribution and that during the evolution of a chemical reaction, grains undergo chemical degradation and phase transitions that could significantly alter the average grain size, or even make the determination of grain size ambiguous if amorphization (Yund et al (1990); Brantut et al. (2008)) is the chemical reaction. As shown by Veveakis et al. (2010); Alevizos and Veveakis (2011) during shearing of faults we may identify a regime of lower temperatures, where mechanical effects determine the evolution of the system and a high temperature regime, where the reaction is triggered and dominates the response of the fault, irrespective of the mechanical behavior. Thus, the present Cosserat approach is valid up to the point that chemical reaction is fully set and determines all the mechanical effects of the fault, like grain size evolutions and rheological response. It is used in order to obtain an estimate of the thickness of the layer at which chemical reaction will be triggered. Pass this point, either discrete analyses or even higher order continuum theories (Stefanou et al. (2010)) must be applied to account for the chemical reaction effects (for example by introducing varying $d_{50}$ ). 


\section{Discussion}

Thermal instabilities were shown to be important at elevated temperatures, and to determine the stability of a fault even at regimes that are considered to be stable under purely mechanical conditions. The formalism presented here however revealed the importance of parameters that are not well-constrained. In particular, the hardening modulus $h$ of rock materials is in principle varying with shear strain, while the parameters of the reaction $A_{0}$ and $T_{c}$ strongly depend on the applied pressures at which the reaction takes place (Lvov (2007), pp. 79) and several values can be found in the literature (For example $A_{0}$ may vary from $10^{2} s^{-1}$ to $10^{20} s^{-1}$ for calcite decomposition, as discused by Lvov et al. (2002)).

Therefore, in order to apply the presented theory in real faults, there is a need of extensive laboratory testing of the strain-stress response of the fault gouge materials and on the effect of pressure and temperature on this response.

The results presented in this work could provide insight for the thermomechano-chemical coupling occurring in soil materials. Given the stressstrain response of the material, the ambient thermal conditions of the fault determine whether the fault may weaken thermally or not. At lower temperatures thermal pressurization may be triggered and cause softening at positive, but near zero, hardening modulus. At higher temperatures, near the activation of chemical reactions thermal softening induces a strong weakening effect since it may take place at extremely high (positive) values of the hardening modulus. Therefore at high temperatures even if the material is mechanically stable (steep hardening regime) the triggering of a chemical 
reaction would lead the system to instability and softening.

The model presented here contains parameters that need to be evaluated from interdisciplinary experiments at conditions that match the ones met in real faults at seismic depths. Parameters like those appearing in the reaction rate of the chemical reaction $\left(A_{0}, T_{c}\right)$ or in friction laws of geomaterials that would provide parameters like $G_{c}$ should be evaluated before applying such models in real cases.

\section{Conclusions}

In this work, we have used higher order continua considerations and allowed to the fault material additional, rotational degree of freedoms, along with the presence of a decomposition reaction. We have shown that the illposed problem of simple shear of a saturated fault can be remedied when accounting for the micro-inertia of the rotations and that, at temperatures near its activation energy, the impact of the reaction is significant to the stability of the mechanical problem and the localization of deformation.

We have shown that the width of the localizing shear zone at which dynamic weakening of faults take place depends strongly on the parameters of the reaction, i.e. the pre-exponential factor $A_{0}$ and the activation temperature $T_{c}$. Small values of the ratio $\frac{A_{0}}{T_{c}}$ correspond to broader zones, of the order of few centimeters.

\section{A. Linear Stability Analysis}

By substituting the perturbation fields (22) into the linearized governing equations $(18,21)$, we obtain a homogeneous algebraic system for the 
539

$$
\left[\begin{array}{ccc}
\frac{s \delta \sigma(d+\epsilon+2 c \mu)}{2 h \lambda \sigma^{\prime}} & \frac{s \delta \sigma(2 f+(a+b) \mu)}{2 h \lambda \sigma^{\prime}} & 0 \\
-\frac{s \alpha \sigma(d+\epsilon+2 c \mu)}{2 h \lambda \sigma^{\prime}} & \frac{s \alpha \sigma(2 f+(a+b) \mu)}{2 h \lambda \sigma^{\prime}} & 0 \\
-s^{2} I-\frac{d}{\lambda^{2}} & -\frac{f}{\lambda^{2}} & \frac{-d+\epsilon}{\lambda} \\
-\frac{c}{\lambda^{2}} & -s^{2} I-\frac{a}{\lambda^{2}} & 0 \\
\frac{-d+\epsilon}{\lambda} & 0 & -2 d+2 \epsilon-\frac{s^{2} I}{2}-\frac{g}{\lambda^{2}}
\end{array}\right.
$$

540

where

$$
\begin{array}{r}
a=\frac{G+K-\left(\mu \beta K^{2}\right) /(G+H+K \beta \mu)}{\sigma}, \\
b=\frac{K-G-\left(\mu \beta K^{2}\right) /(G+H+K \beta \mu)}{\sigma}, \\
c=\frac{-(G \beta K) /(G+H+K \beta \mu)}{\sigma}, \\
\epsilon=\frac{G+G_{c}-\left(G^{2}\right) /(G+H+K \beta \mu)}{\sigma}, \\
f=\frac{-(\mu G K) /(G+H+K \beta \mu)}{\sigma}, \\
g=\frac{G}{\sigma}, K=\frac{G}{1-2 \nu} .
\end{array}
$$

${ }_{541}$ A nonzero solution is possible only when the determinant of the linear 542 system vanishes. This request results in a characteristic polynomial equation 543 of degree 8 for the growth coefficient $s$. If a root has a positive real part, 544 then the corresponding perturbation grows exponentially in time. Since a ${ }_{545}$ polynomial of degree 8 cannot admit an analytic solution, indicative values of the parameters have to be used in order to obtain numerical solutions 

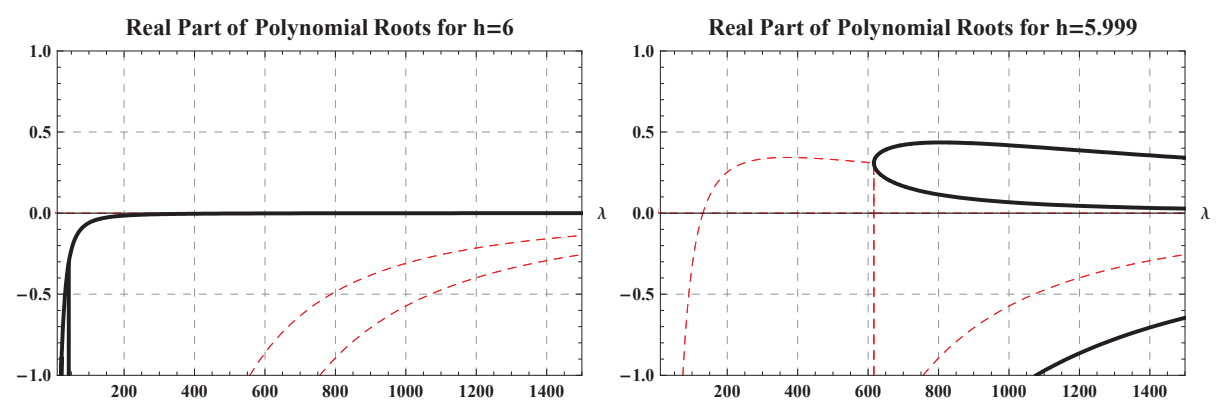

Figure 6: Real parts of the roots of the characteristic equation (growth coefficient $s$ ) as a function of the wavelength number $\lambda$, for $A_{0}=10^{6}$ and $T_{c}=800$ (a) for $h \geq h_{c r}=6$ where only negative roots appear, rendering the system stable, (b) for $h<h_{c r}$. The dashed curves represent the real part of complex roots whereas the solid curves depict the purely real roots (zero imaginary part). The wavelength at which the growth coefficient $s$ obtains its maximum value is the one corresponding to the selected wavelength $\lambda_{m}$.

of the characteristic polynomial. To this end we consider the case of a 7$\mathrm{km}$ deep fault, of a gouge material having the parameters depicted in Table 4.2. With these values we obtain a critical value for the hardening modulus $h_{c r} \approx 6$, such that for $h \geq h_{c r}$ all the roots of the polynomial equation have negative real part, and thus the system is stable (Figure 6a). For $h<h_{c r}$ roots with positive real parts exist, bringing the system to instability (Figure $6 b)$.

In order to asses the localizing effect of the chemical reaction, we may plot the greatest root (i.e. the one corresponding to the instability mode with the fastest growth in time) as a function of the wavelength $\lambda$. This curve exhibits a maximum at $\lambda=\lambda_{m}$ so that a wavelength with the fastest growth in time appears (Figure 6b)

In the absence of thermal pressurization (i.e. when $\Lambda=0$ in the original 

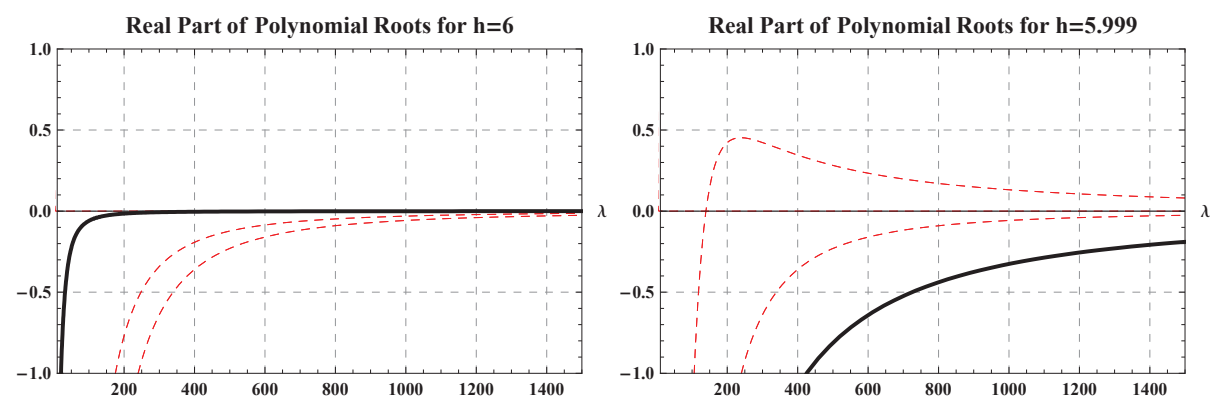

Figure 7: Real parts of the roots of the characteristic equation (growth coefficient $s$ ) as a function of the wavelength number $\lambda$, for $A_{0}=10^{7}$ and $T_{c}=800$ (a) for $h \geq h_{c r}=6$ where only negative roots appear, (b) for $h<h_{c r}$. The dashed curves represent the real part of complex roots, whereas the solid curves depict the purely real roots (zero imaginary part). The maximum root is complex in this case, denoting the onset of oscillatory instability.

set of equations), we rescale temperature with $T_{c}$, recalculate the roots of the characteristic polynomial and plot $s$ against $\lambda$. By comparing the $s-\lambda$ curves of Figures $7 \mathrm{~b}$ and $6 \mathrm{~b}$ with the corresponding ones in the absence of thermal pressurization, appearing in Figure 8, we may conclude that thermal pressurization is a secondary effect at elevated temperatures where the reaction sets in.

\section{Acknowledgments}

The authors would like to thank G. Di Toro, N. Brantut and an anonymous reviewer for their comprehensive reviews and fruitfull comments, from which this paper has greatly benefited.

The research leading to these results has received funding from the European Research Council under the European Community's Seventh Framework Programme (FP7/2007-2013) / ERC grant agreement n 228051. 

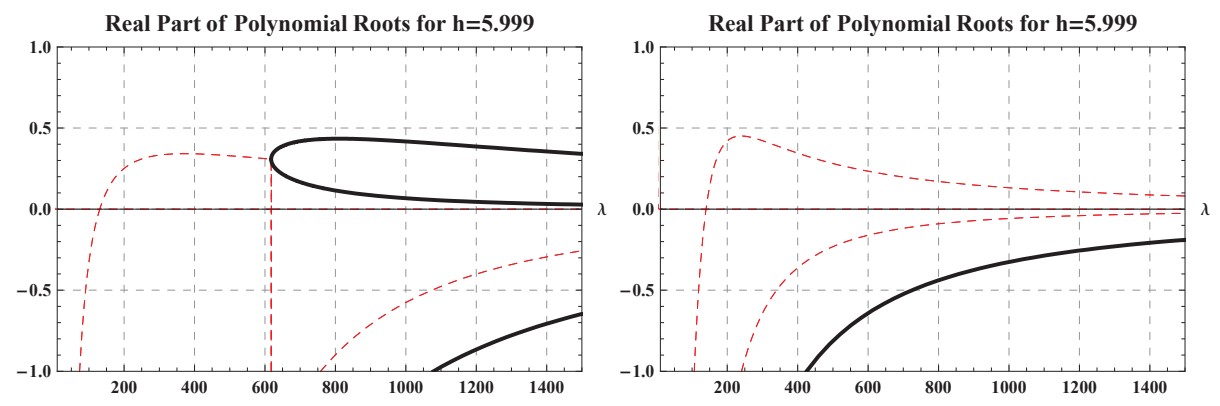

Figure 8: Real parts of the roots of the characteristic equation (growth coefficient $s$ ) as a function of the wavelength number $\lambda$, in the absence of thermal pressurization for $T_{c}=800^{\circ} \mathrm{C}$ and (a) $A_{0}=10^{6} \mathrm{~s}^{-1}$, (b) $A_{0}=10^{7} \mathrm{~s}^{-1}$.

\section{References}

Alevizos, S., Veveakis, E., 2011. Thermal and chemical mechanisms of frictional faults: Static and dynamic instabilities. J. Mech. Phys. Solids in print.

Brantut, N., A. Schubnel, J.-N. Rouzaud, F. Brunet, and T. Shimamoto, 2008. High velocity frictional properties of a clay-bearing fault gouge and im- plications for earthquake mechanics, J. Geophys. Res., 113, B10401, doi: 10.1029/2007JB005551.

Brantut, N., Schubnel, A., Corvisier, J., Sarout, J., 2010. Thermochemical pressurization of faults during coseismic slip. J. Geophys Res. 115, B05314.

Brantut, N., Sulem, J., Schubnel, A., 2011. Effect of dehydration reactions on earthquake nucleation: Stable sliding, slow transients and unstable slip. J. Geoph. Res. 116, B05304, doi:10.1029/2010JB007876.

Brantut, N., R. Han, T. Shimamoto, N. Findling, and A. Schubnel, Fast 
slip with inhibited temperature rise due to mineral dehydration: Evidence from experiments on gypsum, Geology, 39 (1), 5962, 2011.

Chester, F., 1995. A geologic model for wet crust applied to strike-slip faults. J. Geophys. Res. - Solid Earth 100, 13033-13044.

Chester, F., Chester, J., 1998. Ultracataclasite structure and friction processes of the punchbowl fault, san andreas system, california. Tectonophysics, 199-221.

Chester, F. M., Evans, J. P., Biegel, R. L., 1993. Internal structure and weakening mechanisms of the san andreas fault. J. Geophys. Res. 98, 771786.

Chester, J. S., Goldsby, D. L., 2003. Microscale characterization of natural and experimental slip surfaces relevant to earthquake mechanics, SCEC Annu. Prog. Rep. 2003, South. Calif. Earthquake Cent., Los Angeles.

Chester, J.S., Chester, F.M., Kronenberg, A.K., 2005. Fracture surface energy of the Punchbowl Fault, San Andreas System. Nature 437, 133-136.

Cornet, F., Doan, M., Moretti, I., Borm, G., 2004. Drilling through the active Aigion fault: the aig10 well observatory. Comptes Rendus Geosciences 336 (4-5), 395-406.

Di Toro, G., Han R., Hirose, T., De Paola, N., Nielsen, S., Mizoguchi, K., Ferri, F., Cocco, M., Shimamoto, T., 2011. Fault lubrication during earthquakes. Nature, vol. 471, 494-498. 
De Paola, N., Hirose, T., Mitchell, T., Di Toro, G., Togo, T., Shimamoto, T. 2011. Fault lubrication and earthquake propagation in thermally unstable rocks. Geology, vol. 39, pp. 35-38.

Dollimore, D., P. Tong, and K. S. Alexander (1996), The kinetic interpretation of the decomposition of calcium carbonate by use of relationships other than the Arrhenius equation, Thermochim. Acta, 282/283, 1327.

Famin et al., 2008, Earthquakes produce carbon dioxide in crustal faults, Earth and Planetary Science Letters, 265, 487-497.

Ferri, F., Di Toro, G., Hirose, T., Shimamoto, T., 2010. Evidence of thermal pressurization in high-velocity friction experiments on smectite-rich gouges. Terra Nova, 22: 347353, doi:10.1111/j.1365-3121.2010.00955.x.

Fisher, T.E. Tribochemistry. Ann. Rev. Mater. Sci. 18 303-323 (1988).

Garagash, D. I., Rudnicki., J. W., 2003a. Shear heating of a fluid-saturated slip-weakening dilatant fault zone, 1, limiting regimes. J. Geophys. Res. 108.

Garagash, D. I., Rudnicki., J. W., 2003b. Shear heating of a fluid-saturated slip-weakening dilatant fault zone, 2, quasi-drained regime. J. Geophys. Res. 108.

Goren, L., Aharonov, E., 2007. Long runout landslides: The role of frictional heating and hydraulic diffusivity. Geophys. Res. Lett. 34, L07301.

Goren, L., Aharonov, E., Anders, M. H., 2010. The long runout of the Heart 
Mountain landslide:heating, pressurization, and carbonate decomposition. J. Geophys. Res. 115, B10210.

Han, R., Shimamoto, T., Hirose, T., Ree, J., Ando, J., 2007. Ultralow friction of carbonate faults caused by thermal decomposition. Science 316, 878-881.

Han, R., Hirose, T., and Shimamoto, T., 2010, Strong velocity weakening and powder lubrication of simulated carbonate faults at seismic slip rate: Journal of Geophysical Research, v. 115, B03412, doi:10.1029/2008JB006136

Han, R. Takehiro Hirose, Toshihiko Shimamoto, Youngmin Lee and Jun-ichi Ando, 2011, Granular nanoparticles lubricate faults during seismic slip, Geology 2011;39;599-602

Hill, R., 1962. Acceleration waves in solids. J. Mech. Phys. Solids 10, 1-16.

Hirono, T. et al., 2007. A chemical kinetic approach to estimate dynamic shear stress during the 1999 Taiwan Chi-Chi earthquake. Geophys. Res. Lett. 34, L19308, doi:10.1029/2007GL030743.

Holcomb, D.J., Rudnicki, J.W., 2001. Inelastic constitutive properties and shear localization in Tennessee marble, Int. J. Num. Anal. Meth. Geomech. $25,109-129$

Lachenbruch, A. H., Frictional heating, uid pressure, and the resistance to fault motion, J. Geophys. Res., 85, 60976122, 1980.

Law, C., 2006. Combustion Physics. Cambridge University Press. 
L'vov, B., 2007. Thermal Decomposition of Solids and Melts: New Thermochemical Approach to the Mechanism, Kinetics and Methodology. Springer.

L'vov, B. V., Polzik, L. K., Ugolkov, V. L., 2002. Decomposition kinetics of calcite:a new approach to the old problem. Thermochimica Acta 390, $5-19$.

Mandel, J., 1966. Conditions de stabilite et postulate de drucker. Rheology and Soil Mechanics, 58-67.

Morgenstern, N. R., Tschalenko, J. S., 1967. Microscopic structures in kaolin subjected to direct shear. Geotechnique 17, 309-328.

Muhlhaus, H. B., Vardoulakis, I., 1987. Thickness of shear bands in granular materials. Geotechnique 37 (3), 271-283.

Nguyen, G. D., Einav, I., 2010. Nonlocal regularisation of a model based on breakage mechanics for granular materials. Int. J. Sol. Struct. 47, 13501360 .

Noda, H., Shimamoto, T., 2005. Thermal pressurization and slip-weakening distance of a fault: An example of the Hanaore fault, Southwest Japan. Bull. Seismol. Soc. Am. 95 (4).

Pinyol, N., Alonso, E., 2010. Criteria for rapid sliding II.thermo-hydromechanical and scale effects in Vaiont case. Engineering Geology 114, 211227. 
Pittarello, L., Di Toro, G., Bizzarri, A., Pennacchioni, G., Hadizadeh, J., Cocco, M., 2008. Energy partitioning during seismic slip in pseudotachylyte-bearing faults (Gole Larghe Fault, Adamello, Italy). Earth and Planetary Science Letters, vol. 269, pp. 131-139.

Rice, J. R., 1975. On the stability of dilatant hardening for saturated rock masses. J. Geophys. Res. 80 (11), $1531-1536$.

Rice, J. R., 2006. Heating and weakening of faults during earthquake slip. J. Geophys. Res. 111, B05311.

Rudnicki, J., Rice, J., 1975. Conditions for the localization of deformation in pressure sensitive dilatant materials. J. Mech. Phys. Solids 23, 371-394.

Sibson, R. H., Interaction between temperature and pore-uid pressure during earthquake faulting a mechanism for partial or total stress relief, Nature, 243, 6668, 1973.

Sibson, R.H., Thickness of the Seismic Slip Zone, Bull. Seism. Soc. Am., 93, 1169-1178, 2003.

Smith, S. A. F., A. Billi, G. Di Toro, and R. Spiess, Principal slip zones in limestone: Microstructural characterization and implications for the seismic cycle (Tre Monti fault, Central Apennines, Italy), Pure Appl. Geophys., doi:10.1007/s00024-011-0267-5, 2011.

Sulem, J., 2007. Stress orientation evaluated from strain localisation analysis in Aigion fault. Tectonophysics 442, 3-13. 
Sulem, J., Famin, V., 2009. Thermal decomposition of carbonates in fault zones: slip-weakening and temperature-limiting effects. J. Geophys. Res. 114, B03309.

Sulem, J., Stefanou, I., Veveakis, E., 2011. Stability analysis of undrained adiabatic shearing of a rock layer with Cosserat microstructure. Granular Matter in press, doi:10.1007/s10035-010-0244-1.

Sulem, J., Vardoulakis, I., Ouffroukh, H., Perdikatsis, V., 2005. Thermoporo-mechanical properties of the aigion fault clayey gouge - application to the analysis of shear heating and fluid pressurization. Soils and Foundations 45, 97-108.

Stefanou I., Sulem J. and Vardoulakis I., 2010. Homogenization of interlocking masonry structures using a generalized differential expansion technique. International Journal of Solids and Structures 47, 1522-1536.

Tisato, N., Di Toro, G., De Rossi, N., Quaresimin, M., Candela T., 2011. Experimental investigation of flash weakening in limestone. Submitted to Journal of Structural Geology.

Yue, L., Shui, M. and Xu, Z. The decomposition kinetics of nanocrystalline calcite. Thermochimica Acta 335 121-126 (1999).

Yund, R. A., M. L. Blanpied, T. E. Tullis, and J. D. Weeks, Amorphous material in high strain experimental fault gouges, J. Geophys. Res., 95 (B10), 15,58915,602, 1990. 
Vardoulakis, I., 1985. Stability and bifurcation of undrained, plane rectilinear deformations on water-saturated granular soils. Int. J. Numer. Anal. Methods Geomech. 9, 339-414.

Vardoulakis, I., 1986. Dynamic stability of undrained simple shear on watersaturated granular soils. Int. J. Numer. Anal. Methods Geomech. 10, 177190.

Vardoulakis, I., 1996. Deformation of water-saturated sand: II. effect of pore water flow and shear banding. Geotechnique 46 (3), 457-472.

Vardoulakis, I., 2002a. Dynamic thermo-poro-mechanical analysis of catastrophic landslides. Geotechnique 52, 157-171.

Vardoulakis, I., Sulem, J. (Eds.), 1995. Bifurcation Analysis in Geomechanics. Blankie Acc. and Professional.

Veveakis, E., Alevizos, S., Vardoulakis., I., 2010. Chemical reaction capping of thermal instabilities during shear of frictional faults. J. Mech. Phys. Solids 58, 1175 - 1194 .

Veveakis, E., Vardoulakis, I., Di Toro., G., 2007. Thermoporomechanics of creeping landslides: The 1963 Vaiont slide, Northern Italy. J. Geophys. Res. 112, F03026.

Wibberley, C., Shimamoto, T., 2005. Earthquake slip weakening and asperities explained by thermal pressurization. Nature 426 (4), 689-692.

Wibberley, C. A. J., Shimamoto, T., 2003. Internal structure and perme- 
ability of major strike-slip fault zones: The median tectonic line in mid prefecture, southwest japan. J. Struct. Geol. 25, 59-78.

Wibberley , C.A.J, Graham, Y., Di Toro, G., 2008. Recent advances in the understanding of fault zone internal structure: a review. In "The Internal Structure of Fault Zones - implications for mechanical and fluid flow properties", Eds. C.A.J. Wibberley, W. Kurz, J. Imber, R.E. Holdsworth and C. Collettini, Special Volume of the Geological Society of London, Vol. 299, pp. 5-33. 